Supporting Information for

\title{
Activation of Lattice Oxygen in LaFe (Oxy)hydroxides for
} Efficient Phosphorus Removal

Jie Yu, ${ }^{\dagger, \ddagger, \S}$ Chao Xiang, ${ }^{\dagger, \neq, \S}$ Gong Zhang, ${ }^{\S}$ Hongjie Wang, ${ }^{*,+, \ddagger}$ Qinghua $\mathrm{Ji}^{*}{ }^{* \S}$ and Jiuhui $\mathrm{Qu}^{\S}$

† College of Environmental Science and Engineering, Beijing Key Lab for Source Control Technology of Water Pollution, Beijing Forestry University, Beijing 100083, China

$¥$ Xiong’an Institute of Eco-Environment, Hebei University, Baoding 071002, China

$\S$ Center for Water and Ecology, State Key Joint Laboratory of Environment Simulation and Pollution Control, School of Environment, Tsinghua University, Beijing 100084, China 


\section{Table of Contents}

11 pages with 8 Figures and 2 Tables

Table S1. The fitting results and calculated parameters of the Langmuir adsorption isotherm model for phosphate adsorption on the LaFe (Oxy)Hydroxides Adsorbents $\left(25^{\circ} \mathrm{C}\right)$ S5

Table S2. Parameters of kinetics models for phosphate adsorption on the LaFe (Oxy)Hydroxides adsorbents. .56

Figure S1. Scanning electron microscopy (SEM) image of LaFe (Oxy)Hydroxides sample.......S7

Figure S2. Scanning electron microscopy (SEM) image of LOH (a), HR-TEM images of FOH (b), FL5:1(c), FL4:1(d), FL3:2(e), and FL1:1(f).

Figure S3. X-ray diffraction patterns for LaFe (Oxy)Hydroxides sample. S8

Figure S4. Phosphate adsorption performance of as-prepared LOH adsorbents. .S9

Figure S5. Reusability of LaFe (Oxy)Hydroxides regenerated by $1 \mathrm{M} \mathrm{NaOH}$. .S9

Figure S6. FTIR spectra of the as-prepared FOH, LF5:1, LF4:1 and LF2:1 adsorbents before and after $\mathrm{P}$ adsorption, Experimental conditions: adsorbent dosage $=0.5 \mathrm{~g} \mathrm{~L}^{-1}$; initial $\mathrm{P}$ concentration $=50.0 \quad \mathrm{mg} \quad \mathrm{L}^{-1} ; \quad \mathrm{pH} \quad=\quad 7.0 ; \quad$ adsorption $\quad$ time $=24$ h. S10

Figure S7. XPS spectra of FL2:1 before and after phosphate adsorption $\mathrm{S} 10$

Figure S8. Linear combination fit of P K-edge XANES spectra for phosphate adsorbed FL5:1, FL4:1, FL3:2 and FL1:1 samples. Experimental conditions: adsorbent dosage $=0.5 \mathrm{~g} \mathrm{~L}^{-1}$; initial P concentration $=50.0 \mathrm{mg} \mathrm{L}^{-1} ; \mathrm{pH}=7.0$; adsorption time $=24 \mathrm{~h}$. S11 


\section{Section 1: Preparation of LOH}

0.01mol $\mathrm{LaCl}_{3} \cdot 7 \mathrm{H}_{2} \mathrm{O}$ was dissolved into $200 \mathrm{~mL}$ deionized water. Under stirring, 2 $\mathrm{molL}^{-1} \mathrm{NaOH}$ aqueous solution was added dropwise to the solution at $333 \mathrm{~K}$ until $\mathrm{pH}$ 9.0. The mixture was stirred for $2 \mathrm{~h}$ and aged for $24 \mathrm{~h}$ at $333 \mathrm{~K}$. Precipitates were washed three times with deionized water and freeze-dried for $24 \mathrm{~h}$.

\section{Section2: Equations used in this study}

\section{Langmuir model}

The experimental results are fitted for by using Langmuir (Langmuir., 1916) (Equation (S5)) isotherm models (Freundlich., 1906), respectively.

$$
q_{e}=\frac{q_{\max } K_{L} C_{e}}{1+K_{L} C_{e}}
$$

where $q_{e}$ is the equilibrium amount of phosphate adsorbed on adsorbent $\left(\mathrm{mg} \cdot \mathrm{g}^{-1}\right)$; $q_{\max }$ is the maximum amount of phosphate adsorbed $\left(\mathrm{mg} \cdot \mathrm{g}^{-1}\right) ; C_{e}$ is the equilibrium concentration of phosphate $\left(\mathrm{mg} \cdot \mathrm{L}^{-1}\right) ; K_{L}$ is the Langmuir adsorption constant $\left(\mathrm{L} \cdot \mathrm{mg}^{1}\right)$;

\section{Kinetic model}

The mass flow rate of phosphate is calculated using the following equation:

$-\frac{d C}{d t}=k_{f} a\left(C-C_{s}\right)$

where $k_{f}$ is the mass transfer coefficient $(\mathrm{m} / \mathrm{s}), a$ is the effective area for mass transfer per unit volume of the contactor, $C$ is concentration of phosphate in solution, and $C_{S}$ is the concentration of phosphate at the surface of adsorbent.

In the Langmuir model, the adsorption capacity $\left(q_{e}\right)$ can calculated using

$q_{e}=\frac{V}{m}\left(C_{0}-C_{s}\right)$

Where $V$ is the contactor volume $(0.05 \mathrm{~L}), m$ is the mass of adsorbent $(0.2 \mathrm{~g})$, and $C_{0}$ is the initial concentration of phosphate in solution.

By combining Eqs. (S1), (S2) and (S3), we obtain Eq. (S4):

$-\frac{d C}{d t}=K_{f} a\left[C-\frac{1}{2}\left(\sqrt{\left(\frac{q_{m} m}{V}-C_{0}+\frac{1}{K_{L}}\right)^{2}+\frac{4 C_{0}}{K_{L}}}-\frac{q_{m} m}{V}+C_{0}-\frac{1}{K_{L}}\right)\right]$

According to Eq. (S4), we can derive the concentration of phosphate $(C)$ as a function of time (t) to describe the adsorption: 
$C=\operatorname{bexp}[-h t]+C_{0}-b$

Where $h$ is the fitting parameter, representing $k_{f} a$. Thus, Eq. (S5) can be used to fit experimental results and estimate $k_{f}$. 
Table S1 - The fitting results and calculated parameters of the Langmuir adsorption isotherm model for phosphate adsorption on the LaFe (Oxy)Hydroxides adsorbents $\left(25^{\circ} \mathrm{C}\right)$.

Parameters of isotherm models for adsorption of phosphate on adsorbents

\begin{tabular}{cccccc}
\hline Temperature $^{\mathrm{a}}$ & $150^{\circ} \mathrm{C}$ & $150^{\circ} \mathrm{C}$ & $150^{\circ} \mathrm{C}$ & $120^{\circ} \mathrm{C}$ & $180^{\circ} \mathrm{C}$ \\
$\mathrm{pH}^{\mathrm{b}}$ & 8 & 10 & 12 & 10 & 10 \\
\hline $\mathrm{K}_{\mathrm{L}}$ & 0.0283 & 0.0441 & 0.0338 & 0.0906 & 0.0474 \\
$\mathrm{Q}_{\mathrm{m}}$ & 119.0746 & 123.4568 & 103.0928 & 78.7402 & 75.1880 \\
$R^{2}$ & 0.9924 & 0.9951 & 0.9826 & 0.9987 & 0.9876 \\
\hline
\end{tabular}

a-Temperature of solvothermal treatment during preparation of LaFe (Oxy)Hydroxides adsorbents.

b- $\mathrm{PH}$ of citric acid monohydrate solution during preparation of LaFe (Oxy)Hydroxides adsorbents.

Parameters of isotherm models for adsorption of phosphate on adsorbents

\begin{tabular}{ccccccc}
\hline & FOH & FL5:1 & FL4:1 & FL2:1 & FL3:2 & FL1:1 \\
\hline $\mathrm{K}_{\mathrm{L}}$ & 0.0594 & 0.0526 & 0.0914 & 0.0441 & 0.2254 & 0.1519 \\
$\mathrm{Q}_{\mathrm{m}}$ & 21.5054 & 61.7284 & 50.5051 & 123.4568 & 63.2911 & 74.0741 \\
$R^{2}$ & 0.9864 & 0.9950 & 0.9971 & 0.9951 & 0.9988 & 0.9969 \\
\hline
\end{tabular}


Table S2- Parameters of kinetics models for phosphate adsorption on the LaFe (Oxy)Hydroxides adsorbents.

Parameters of kinetic models for adsorption of phosphate on adsorbents $\left(150^{\circ} \mathrm{C}\right)$

\begin{tabular}{ccccccc}
\hline Mass Transfer Model & FOH & FL5:1 & FL4:1 & FL2:1 & FL3:2 & FL1:1 \\
\hline$h\left(\mathrm{~s}^{-1}\right)$ & 0.1055 & 00436 & 0.0261 & 0.0605 & 0.0389 & 0.0237 \\
$k_{f}\left(10^{-6} \mathrm{~m} / \mathrm{s}\right)$ & 9.4239 & 2.1482 & 1.3924 & 4.1112 & 3.8307 & 2.4058 \\
$R^{2}$ & 0.8550 & 0.9667 & 0.9833 & 0.9065 & 0.8957 & 0.7746 \\
\hline
\end{tabular}



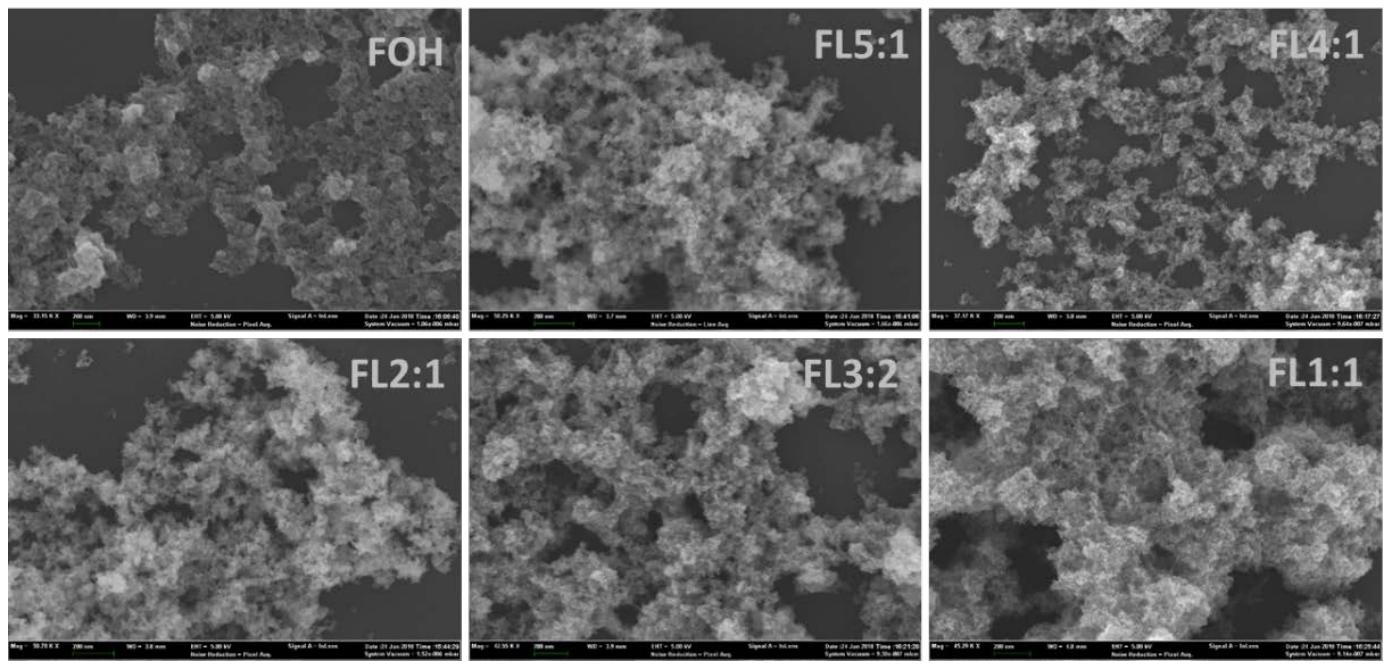

Figure S1. Scanning electron microscopy (SEM) image of LaFe (Oxy)Hydroxides sample.
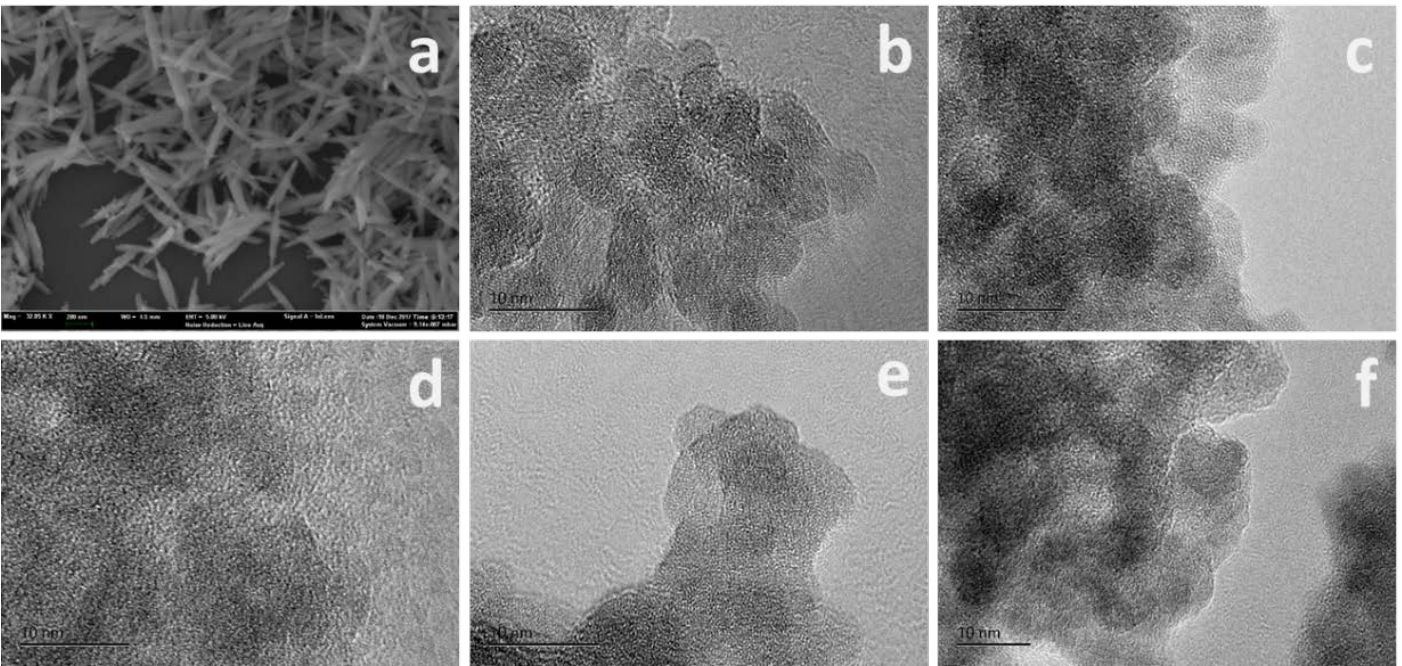

Figure S2. Scanning electron microscopy (SEM) image of LOH (a), HR-TEM images of FOH (b), FL5:1(c), FL4:1(d), FL3:2(e), and FL1:1(f). 


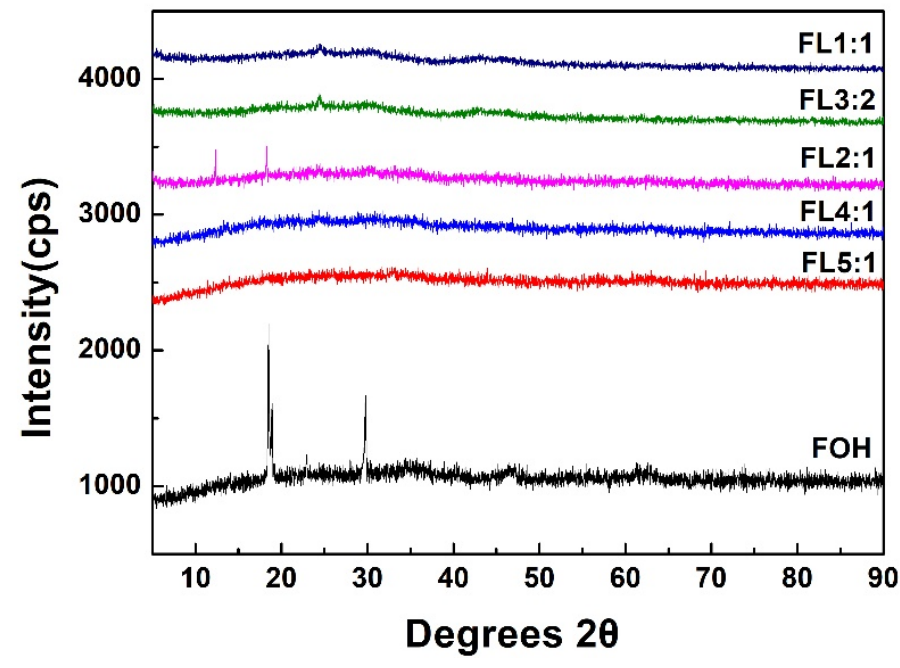

Figure S3. X-ray diffraction patterns for LaFe (Oxy)Hydroxides sample. 


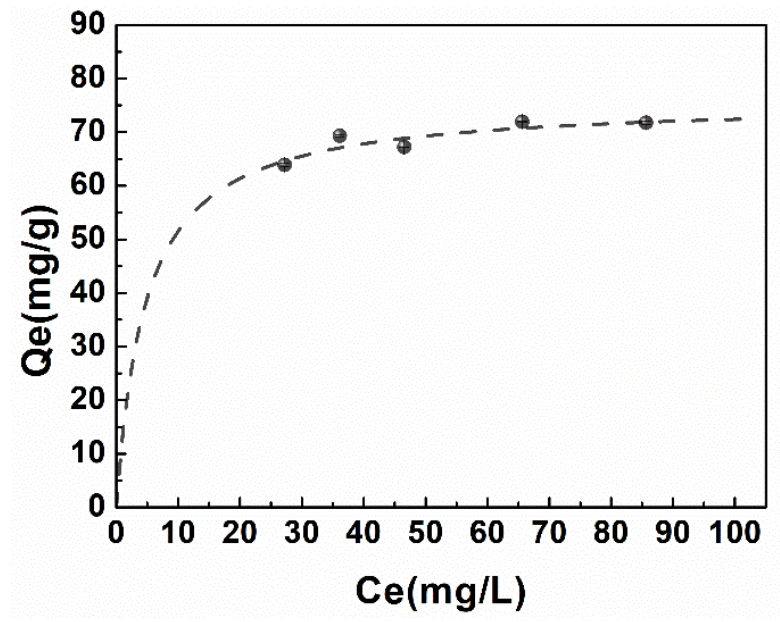

Figure S4. Phosphate adsorption performance of as-prepared LOH adsorbents.

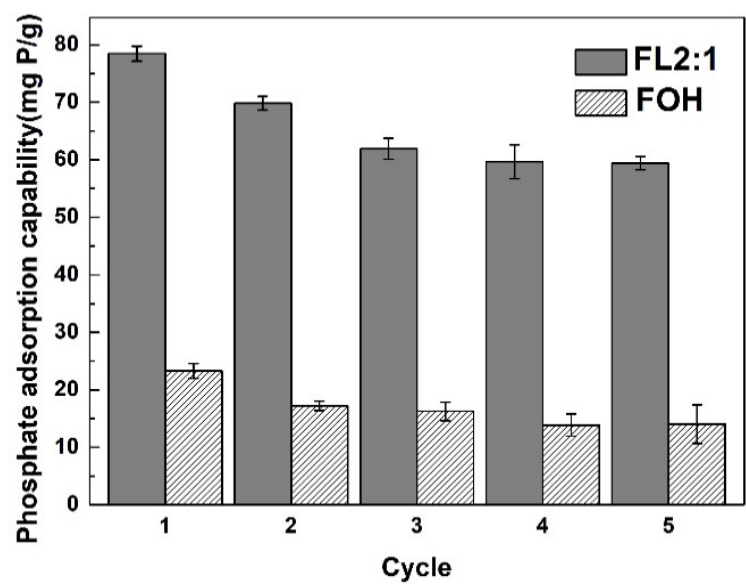

Figure S5. Reusability of LaFe (Oxy)Hydroxides regenerated by $1 \mathrm{M} \mathrm{NaOH}$. 


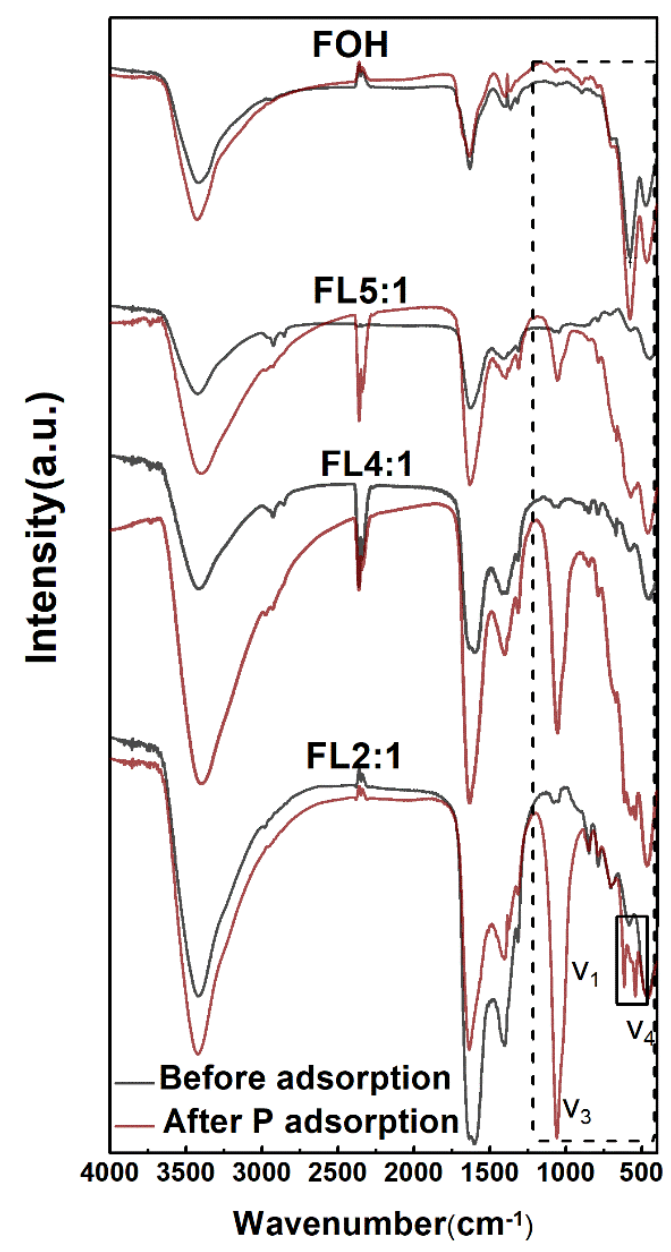

Figure S6. FTIR spectra of the as-prepared FOH, LF5:1, LF4:1 and LF2:1 adsorbents before and after $\mathrm{P}$ adsorption, Experimental conditions: adsorbent dosage $=0.5 \mathrm{~g} \mathrm{~L}^{-1}$; initial $\mathrm{P}$ concentration $=50.0 \mathrm{mg} \mathrm{L}^{-1} ; \mathrm{pH}=7.0$; adsorption time $=24 \mathrm{~h}$.

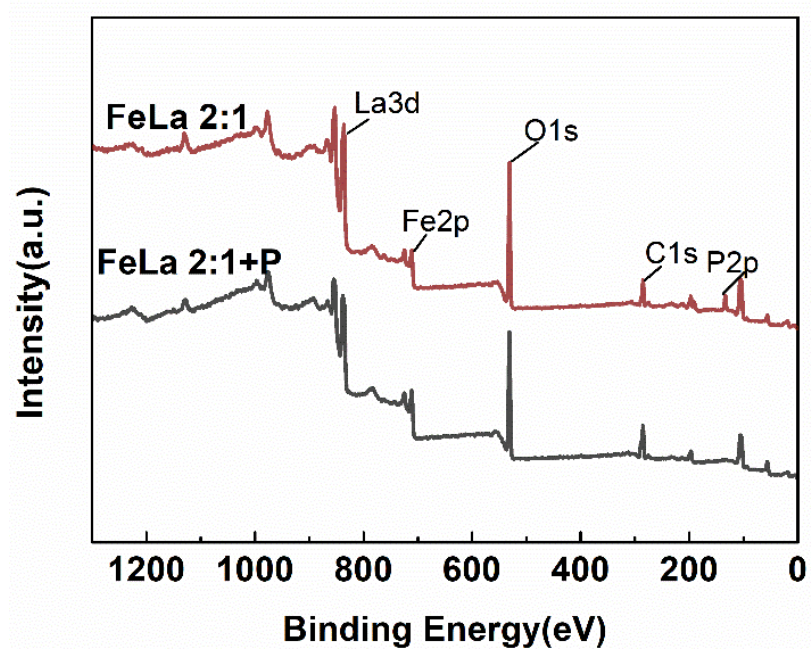

Figure S7. XPS spectra of FL2:1 before and after phosphate adsorption. 

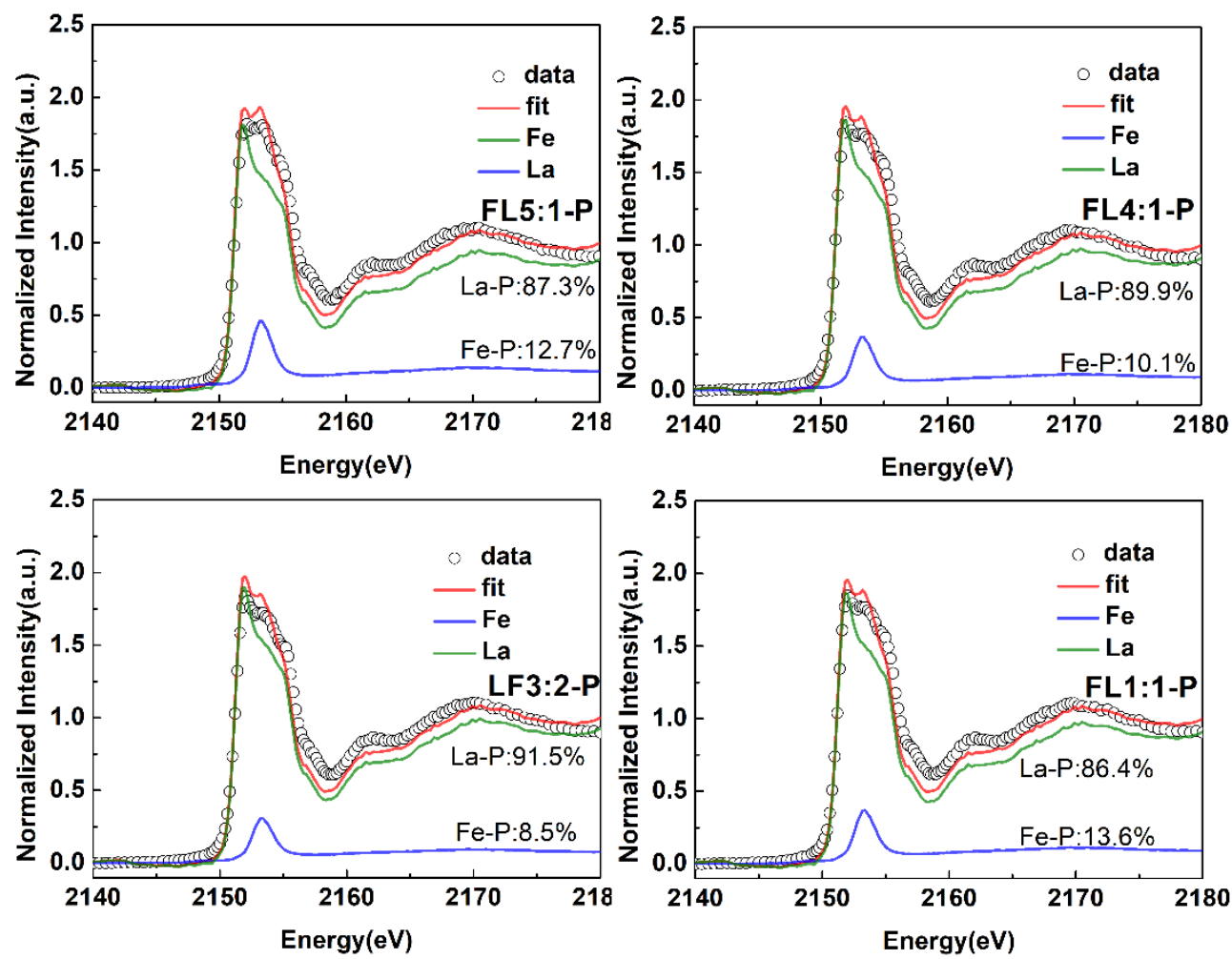

Figure S8. Linear combination fit of P K-edge XANES spectra for phosphate adsorbed FL5:1, FL4:1, FL3:2 and FL1:1 samples. Experimental conditions: adsorbent dosage $=0.5 \mathrm{~g} \mathrm{~L}^{-1}$; initial P concentration $=50.0 \mathrm{mg} \mathrm{L}^{-1} ; \mathrm{pH}=7.0$; adsorption time $=24 \mathrm{~h}$. 